O SR. ARMANDO DIAS DE AZEVEDO - Peço a palavra, senhor Presidente.

O SR. PRESIDENTE - Tem a palavra o nobre congressista. O SR. ARMANDO DIAS DE AZEVEDO - Parece-me que as primeiras conclusões estão inplìcitamente votadas. A divergência é, justamente, da terceira em diante. Seria o caso de considerá-las prejudicadas e votarmos só da terceira em diante.

O SR. PRESIDENTE - Vou, então, dá-las por aprovadas. Serão agora votadas as três últimas.

$O$ SR. ARMANDO DIAS AZEVEDO - V. Excia. permite?

O SR. PRESIDENTE - Pois não.

O SR. ARMANDO DIAS DE AZEVEDO - Esta terceira proposição é constante do parecer. Porém, é voto vencido no seio da Comissão. Parece-me, pois, que deve ser submetido à votação o ponto de vista da maioria da Comissão. Este é o parecer, e não o voto vencido.

O SR. PRESIDENTE - Pois bem, a aceitação de um implica na rejeição de outro.

O SR. BRUNO DE MENDONÇA LIMA - Peço a palavra, senhor Presidente.

O SR. PRESIDENTE - Tem a palavra o nobre congressista.

O SR. BRUNO DE MENDONÇA LIMA - Senhor Presidente. era exatamente isso que eu queria dizer, a rejeição de um implica na aceitação de outro.

Estou, pois, plenamente de acôrdo.

Sera, então, desnecessária outra votação.

(Palmas.)

O SR. PRESIDENTE - E, pois, desnecessária a votação.

\section{PROPOSIÇÃO CONCERNENTEE À CRIAÇÃO DA CADEIRA DE DIREITO CIVIL COMPARADO, E DE UM INSTITUTO QUE TENHA POR FINALIDADE O ESTUDO COMPARATIVO DO DIREITO EM TODOS OS SEUS RAMOS.}

\section{Magdalena Londero}

Consultor jurídico do D.P.M. do Rio Grande do Sul. Curso de Doutorado da Faculdade de Direito da Universidade de Paris

Assim como em qualquer ramo do conhecimento o indivíduo não se contenta hoje em saber o que foi escrito e realizado concernente à sua especialidade, dentro das fronteiras de seu País, com maior razão o jurista deve empenhar-se em conhecer o direito dos outros Povos.

Ao jurista não se permite atualmente ignorar o estado e a evolução da ciência jurídica fora do seu País. Como bem observou o ilustre professor da Universidade de Cambridge, M. Harold C. GUTTERIDGE, "Nous avons beaucoup à apprendre les uns des autres en matière de droit comme dans les autres matières, et c'est une honte pour les juristes qu' ils se soient révélés incapables jusqu'ici de parvenir à un libre échange de connaissances et d'idées, comme on y est parvenu dans les autres branches des études humaines." ( $\left.{ }^{1}\right)$

E conforme um outro grande professor da matéria, na Faculdade de Direito da Universidade de Paris, M. René David, para quem o Direito comparado é um método comparativo aplicado à ciência jurídica - todo jurista deve ser um comparatista. Assim diz êle: "Le pénaliste, cherchant à juger ou à réformer notre régime pénitentiaire, doit connaître les expériences qui ont pu être tentées à l'étranger et qui peuvent lui offrir un modèle ou au contraire l'amener à réfléchir sur le danger de certaines innovations. Le civiliste, qui se demande ce qu'il faut entendre pas cas de force majeure ou qui cherche à préciser les contours de la théorie de l'abus des droits, doit tirer parti des réflexions et des études qui ont pu être faites sur se même sujet par un grand juriste étranger. Le commercialiste, qui étudie les tecniques bancaires, ne joue pas le rôle qui lui est dévolu s'il se limite

(1) Citado por M. René DAVID - Traité élémentaire de Droit Civil Comparé - 
à étudier ce point sur le terrain du seul droit français. Dans tous les domaines la méthode comparative peut, en de nombreuses hipothèses, être employée avec fruit. Le juriste qui n'est pas apte a l'employer est privé d'un moyen, souvent essentiel, à l'aide duquel il peut être appelé à accomplir sa tâche; il ne connaît qu'imparfaitement son métier, et ce n'est pas une excuse, pour lui, de dire qu'il n'est pas un comparatiste: tout juriste qui veut être à la hauteur de sa tâche doit êre un comparatiste.” (1)

Assim, e, considerando , que :

- As circunstâncias político-sociais-econômicas pelas quais atra vessa o mundo presentemente, estão a exigir um grande esfôrço de compreensão por parte de todos e principalmente daqueles que desejam constituir uma elite.

- Os verdadeiros juristas devem fazer um esfôrço para melhor conhecer o direito dos outros Povos e dêste modo poder julga suas instituições e sua política.

- O estudo do direito comparado nos leva a aumentar as relações culturais, e a trabalhar assim para uma maior aproximação entre os Povos.

- Por falta de um plano de conjunto, o estudo de certos problemas, permanecendo entregues à iniciativa e ao trabalho individual, permanecem muitas vêzes negligenciados, quando não esquecidos.

\section{Propomos :}

- A criação, nas Faculdades de Direito, da Cadeira de Direito Civil Comparado.

- A criação de um Instituto que tenha por finalidade o estudo do direito comparado em todos os seus ramos.

\section{PARECER E DEBATES EM PLENÁRIO}

Relator :

Dorival Schmitt

O SR. PRESIDENTE - José Salgado Martins - (na ausência eventual do Sr. J. C. Bonazzola). Temos sôbre a Mesa uma proposição concernente à criação da Cadeira de Direito Civil Com-

(1) M. R. David - Cours de Dreit Civil Comparé - 1948 1949, pag. 15. parado e de um Instituto que tenha por finalidade o estudo comparativo do Direito, em todos os seus ramos.

$\mathrm{O}$ relator é o dr. Dorival Schmitt, a quem concedo a palavra.

O DR. DORIVAL SCHMITT - Sr. Presidente, srs Congressistas.

Na comissão de Direito Civil, a dra. Madalena Londero apresentou uma proposição no sentido de que se criasse no Rio Grande do Sul um Instituto de Direito Comparado e nos cursos da Faculdade de Direito da Universidade do Rio Grande do Sul uma cadeira de Direito Civil Comparado.

De acôrdo com o processo adotado em nossa comissão, a Comissão de Direito Civil, fui nomeado relator, imediatamente, para, oralmente, emitir meu parecer, o qual foi manifestado no seguinte teor:

À Comissão de Direito Civil não caberia o encaminhamento dessa proposição, muito menos ao Congresso, nos têrmos em que ela estava vasada, ou seja, de que ao Congresso Nacional se encaminhasse um assunto de interêsse local, do Rio Grande do Sul, afeto à entidade e dos órgãos existentes dentro da nossa própria Universidade, quais sejam a Congregação da Faculdade de Direito e o Conselho Universitário. Porém, no caráter de recomendação, e sendo extensiva a proposta às Universidades e Faculdades de Direito do País, era de ser adotada, uma vez que pelos fundamentos da proposição da dra. Madalena Londero, aliás feita com muito acêrto, o Brasil está necessitando no seu âmbito de ensino jurídico, da instituição dêsse órgão, ou seja, do Instituto de Direito Comparado, em tôdas as suas Universidades oficiais.

Aliás, o trabalho da professôra Madalena Londero está baseado em observações por ela feitas na viagem que realizou à Europa, onde teve ensêjo de entrar em contato com diversos Institutos de Direito Comparado. Quanto à cadeira de Direito Civil Comparado, o caso seria de transferi-la do curso de doutorado para o curso de bacharelato, uma vez que naquele ela já existe, segundo nosso sistema de ensino superior, embora sua existência não atenda as nossas necessidades, visto que não se encontra em funcionamento êsse curso no Brasil.

De sorte que a Comissão, examinando o caso, chegou à seguinte conclusão: em primeiro lugar, concorda com a necessidade, e portanto propõe ao Congresso, que recomende a criação de um Instituto de Direito Comparado, nas diversas Universidades do Brasil, bem como a transferência da cadeira de Direito Civil Comparado, do curso de doutorado para o de bacharelato.

$\hat{E}$ apenas isso o que tinha a dizer. (Palmas)

O SR. PRESIDENTE - Está em discussão a proposição. 
O SR. BRUNO DE MENDONÇA LIMA - Peço à palavra sr. Presidente

O SR. PRESIDENTE - Concedo a palavra ao sr. Bruno de Mendonça Lima.

O SR. BRUNO DE MENDONÇA LIMA - Sr. Presidente, srs. Congressistas.

$\mathrm{O}$ trabalho em discussão parece-me de grande relevância, não só para o estudo das ciências jurídicas, como para a nossa produção legislativa.

Tenho para mim que um dos serviços mais importantes do atual Congresso Jurídico, é justamente procurar aperfeiçoar o nosso Direito Positivo.

Em matéria de legislação, temos ficado muitas vêzes entre dois extremos: ou copiamos de língua estrangeira, e copiamos mal, ou inventamos uma lei que não tem raízes nem na doutrina nem nos nossos costumes.

O grande remédio para isso é o Direito Comparado. Houve tempo em que essa cadeira foi ensinada nas Faculdades de Direito. Entretanto, eram todos os ramos de direito estudados, comparativamente, numa cadeira só, num ano apenas, o que era completamente ineficiente. Aliás, uma cadeira de Direito Comparado não terá eficiência alguma se não houver um Instituto de Direito Comparado, que tenha intercâmbio de material entre juristas do nosso e dos diferentes países.

Muitas vêzes, nos debatemos com problemas que já afligiram outros povos que os resolveram satisfatòriamente, por meio de leis que foram várias vêzes reformadas até atingir forma mais perfeita. E nós desconhecemos tudo isso, porque não havendo um Instituto de Direito Comparado, por maior que seja a nossa boa vontade, não temos meios de conhecer o que vai pelo mundo em matéria de legislação.

Quer me parecer, porisso, que esta proposição merece o aplauso do Congresso. A criação de um Instituto de Direito Comparado e a instituição de uma cadeira. de Direito Civil Comparado, em cada uma de nossas Universidades contribuiria, imensamente, para elevar o nível cultural brasileiro, e, principalmente, para o aperfeiçoamento da nossa legislação. (Palmas)

A SRA. MADALENA LONDERO - Peço a palavra, sr. Presidente.

O SR. PRESIDENTE - Tem a palavra a doutora Madalena Londero.

A SRA. MADALENA LONDERO - Preliminarmente, sr. Presidente, srs. Congressistas, eu desejaria fazer uma ressalva na oração do dr. Dorival Schmitt. É que a proposição que eu tive a ousadia de apresentar a êste Congresso, eu a apresentei como simples Congressista e como estudiosa do Direito, e não como professôra porque não tenho a honra de o ser.

Tomei a liberdade de propor a êste Congresso não sòmente a criação da cadeira de Direito Civil Comparado, como também a instituição de um Instituto de Direito Comparado, que tivesse por finalidade o estudo dos diferentes ramos do Direito, nos diferentes países, porque julguei a ocasião propícia para o mais amplo debate da questão, pois que justamente neste Congresso estão reunidos professôres das várias Faculdades, magistrados e estudiosos do Direito:

Por conseguinte, esta a ocasião mais oportuna para um debate sôbre êste tema, pois, como frisei na Comissão que me deu a honra de aceitar-me finalidade de permitir o debate em tôrno do assunto que ela contém.

Por outro lado, o entusiasmo que me levou a apresentar essa proposição se deve à minha estadia na França, onde entrei em contato com diferentes órgãos de ensino e que me levou a constatar o grande entusiasmo de todos os estudiosos do Direito, por todos os ramos da ciência jurídica.

No ano de 1948, pela primeira vez, na Faculdade de Direito de Paris foi ministrado ensino do Direito Brasileiro, com grande assistência, despertando o maior interêsse. Ainda em Paris, no Colécio fe Frana a primeira cadeira de Direito légio de França, em 1869 , foi instalada a primeira Sociedade de Direito Comparado; em Lyon, em 1920, o primeiro Instituto de Direito Comparado.

Hoje, vários institutos existem em diferentes países, e tive oportunidade de visitar o Instituto de Direito Comparado, que funciona em Roma. Podemos dizer mesmo que aqui na América, foi fundada, em 1945, a Academia Inter-Americana de Direito Comparado e de Direito Internacional, que funciona em Havana, cujos cursos são publicados em língua espanhola, inglêsa e portuguêsa.

Existe a UNESCO, da Organização das Nações Unidas, para a diectias sociais, edue visa intercâmbio de professôres e alunos de diferentes $\mathrm{Fa}$ que visa o intercâmbio de professores e aluno do Direito Comparado.

Entre os seus objetivos, que são o de favorecer o conhecimento compreensão mútua das nações entre si, se inclui o de dar um vigoroso impulso ao ensino do Direito, em todos os seus diferentes ramos

Eu tenho a convicção de que sòmente no dia em que procurarmos nos conhecer mùtuamente, haverá maior compreensão entre os diferentes povos, e o Direito, como ciência viva que é, nos le- 
vará a melhor estudar a geografia, a história, as condições sociais e políticas de cada povo.

Creio, também, que a fundação de um Instituto de Direito comparado, que será anexo às Universidades, permitirá o desenvolvimento, em trabalhos coletivos - porque os trabalhos individuais, podemos usar a expressão, muitas vêzes permanecem engavetados - permitirão não sòmente o debate dêste problema, como também a realização de melhores obras no campo do Direito.

Êstes os motivos que me levaram à proposição, que ora se discute. (Palmas)

O SR. PRESIDENTE - Se nenhum Congressista quiser mais se pronunciar a respeito desta indicação, passaremos à votaçãa. Os srs. Congressistas que aprovam a proposição da professôra Madalena Londero, queiram ter a bondade de permanecer sentados. Aprovada. (Palmas)

\section{3. ${ }^{\mathrm{a}}$ SECÇÃO \\ DIREITO MERCANTIL E DIREITO MERCANTIL COMPARADO}

\section{COMISSẼO}

Prof. Dr. Ney Wiedemann

Prof. Dr. Ernani Estrella

Prof. Dr. Paulo Barbosa Lessa

Prof. Dr. Edgar Luiz Schneider

Prof. Dr. Antônio Martins Filho

Prof. Dr. Júlio César Bonazzola Dr. José Baptista Neto

Prof. Dr. Ernesto Martins Vieira 